\title{
The Pragmatic Comparison of Chinese and Western "Politeness" in Cross-cultural Communication
}

\author{
Jiang Zhu \\ School of Foreign Languages, Changchun University of Science and Technology, Changchun, China \\ Email: zhujiang98@163.com \\ Yuxiao Bao \\ School of Foreign Languages, Changchun University of Science and Technology, Changchun, China \\ Email: baoyuxiao2005@yahoo.com.cn
}

\begin{abstract}
Theoretical research on "politeness" of China and western countries has explained the concept of "politeness" in Chinese and western cultures. This paper analyzes the similarities and differences of Chinese and western cultures from the aspects of connotation of "politeness", its choice preference and the way of expression and clarifies that only by correct use of politeness principles can people get the best effect of communication.
\end{abstract}

Index Terms-pragmatic comparison, politeness, cross-cultural communication

\section{INTRODUCTION}

With the rapid development of globalization, cross-cultural communication has been a more and more important part in people's ordinary life. It becomes rather important about how to communicate properly and politely with people in different cultural backgrounds. The paper tries to probe into Leech's "politeness principle" (Leech, 1983, p.135), aiming firstly to form a scientific and correct cognition of "politeness principle" through analyzing the concrete manifestation of politeness principle in cross-cultural communication between China and western countries; secondly, to help communicators avoid unnecessary pragmatic failure of politeness and to make the realization of cross-cultural communication successfully.

As a scientific knowledge which aims to study how the language users use and comprehend language in a certain context, pragmatics is closely related to cross-cultural communication. Leech's politeness principle is put forward on the basis of the summarization of some verbal communication disciplines and many experts consider it as universal (Leech, 1983). However, like other theories, it is based on western culture and regards westerners' way of utterance as the universal way of utterance of people. But this point makes it always be questioned in the linguistic field. It is both the dominating research topic of cross-cultural pragmatics and the topic which will be investigated - about the extent to which the politeness principle is universal and to what extent it reflects the individuality restricted by different cultures under the situation of cross-cultural communication.

Cross-cultural communication usually refers to the communication between any two people under different cultural background. It includes not only the international cultural communication, but also communication across different races or ethnic groups in the same country, and communication between different groups under the same culture. Here we mainly talk about verbal communication between different ethnic groups. In cross-cultural communication, cultural differences play an important role in speech act and in the disciplines in use of speech. Moreover, people tend to use the principles of their own culture as the standard to explain and evaluate other people's behavior. This is what is called "pragmatic transfer" (He, 2000, p.98). Due to this, pragmatic failure occurs easily and the cross-cultural communication is blocked.

\section{The TheORETICAL ReSEARCH ON "POLITENESS" IN CHINA AND WeStern COUNTRIES}

Politeness is a kind of social phenomenon, an approach used in order to maintain the harmonious interpersonal relationship, and a kind of conventional behavioral norms. It is a standard of behavior that everyone must follow no matter what his culture is. There are different standards of politeness in different cultural backgrounds of society. The diversities are reflected mainly through the definitions of politeness, the strategy of realization of politeness, etc. (Gu, 1992). So politeness is specific under different cultural backgrounds. This specificity is closely related to cultural values which are influenced by social, historical, geographical and other elements. The subject of politeness is one important aspect in both Chinese and western pragmatics and the research on it had a long history.

A. The Concept of "Politeness" in Western Culture 
As for theory frame, the face theory of Brown and Levinson and the politeness principle of Leech are relatively influential among them. These two theories make a systematic and profound research on the connotation and denotation of politeness, which influences a lot on researches of politeness of different cultures. Brown and Levinson's concept of face is based on the definition given by Goffman. According to Goffman's theory, face is sacred and inviolable to every single person and it is the most basic and can not be neglected to every communicator (Gao, 1997). The concept proposed by Brown and Levinson is more concrete. They believe that each rational member of society has his own face and they divide face into two groups according to individual need: negative face and positive face. The former means that people have the freedom of action without interference while the latter means that the desire to be approved or the positive individual image to be praised. Face has duality and the dual aspects constituting face is contradictory. In communication, on one hand, we need to interact with the other person involved or pay close attention to him. At the same time, we need to show our attention. The interaction aspect is positive face and Levinson distinguish it as positive politeness. The discourse strategy which "positive face" usually makes use of is: to listen to the other's speech with respect and show an interest in it; to make it clear that the two communicators have something in common, etc. For example, "I agree. I have always believed that, too." On the other hand, we should protect certain independence and express that we respect their independent demand to the other side. The independent aspect of politeness is acknowledged as negative face, which is distinguished as "negative politeness" by Levinson. The main strategies to implement negative face are: to speculate the others' need and interest to the minimum degree; not to impose one's own opinion to the others; to give the others the right to make his own choice. For example, if you intend to give suggestion to others, you might say, "I'd enjoy going out for coffee, but I imagine you are very busy."(Gao, 1997, p.25) The key in the negative face implementation is not to impose a certain idea to others, in order to make the counterparts enjoy enough freedom and independence. In real life, the most communicative acts are face-threatening acts. Sometimes you express your disagreement to others, complain or blame on others' work; sometimes you utter some impolite words or taboos. These all belong to face-threatening acts. This is because the speaker does not consider other communicators' social value. The acts like command or request will threat negative face. If the other side of a conversation acts follows the speaker's command of request, the hearer's freedom of action is interrupted under the speaker's imposition. In order to avoid or lessen the threat degree to faces and maintain the communication going on favorably, the speaker must do certain efforts for protecting both his and the hearer's faces. It is distinguished as politeness. The British linguist Leech had listed six politeness principles according to the English culture (Leech, 1983):

Tact Maxim: try to minimize cost to other or maximize benefit to other;

Generosity Maxim: try to minimize benefit to self or maximize cost to self;

Approbation Maxim: try to minimize dispraise of other or maximize praise of other;

Modesty Maxim: try to minimize praise of self or maximize dispraise of self;

Agreement Maxim: try to minimize disagreement between self and other or maximize agreement between self and other;

Sympathy Maxim: try to minimize antipathy between self and other or maximize sympathy between self and other.

\section{B. The Concept of "Politeness" in Chinese Culture}

Many Chinese scholars have done researches on the phenomenon of "politeness" and proposed their own views and theories. In Professor Gu Yueguo's book Pragmatic Politeness and Culture, he believes that there are four basic concepts in traditional Chinese "politeness". They are respectfulness, modesty, attitudinal warmth and refinement (Gu, 1992). Respectfulness is to affirm others' faces and social status; modesty can be taken as another way of saying debasing oneself; attitudinal warmth refers to the expression of friendliness and concern from self to others; refinement refers to choosing elegant expression and forbidding bawdry. According to Professor He Zhaoxiong, compared with Brown and Levinson's concept of face, the perception of respectfulness is to respect the other's positive face (He, 2000). In a broad sense, the perception of modesty lies in different cultures, but it is explained into debasing oneself only in Chinese culture. Brown and Levinson believe that the conception of attitudinal warmth not only violates the freedom of others, but also threats others' negative face. In contemporary Chinese language, this is not believed as face-threatening act. The conception of refinement is the representative of the politeness normativeness. Although politeness is universal, there is no mention of "refinement" in Brown and Levinson's research. Professor Gu Yueguo proposed a sequence of principles on the basis of the combination of four basic concepts in traditional Chinese "politeness" and Leech's politeness principle - respectfulness, modesty, attitudinal warmth, refinement, tact maxim and generosity maxim, which are fit for the contemporary Chinese language.

\section{The Cultural DifFERENCES BETWEen ChInESE POLITENESS AND WeSTERn Politeness}

In any society or group all around the world, people's behavior is restricted by "politeness" and maintained by "face". In Chinese society, the etiquette is advocated. The formation and development of "etiquette" and its restriction on people's behavior all have more special meaning than in any other country and society in the world. The "politeness principle" in Chinese society restricted by "etiquette" is to a great extent different from that of western countries in nature. The differences are various. To be more concrete, the differences are exemplified in the connotation of politeness, the focus or choice of politeness principle, the way of expression of politeness, etc. 


\section{A. The Connotation Differences between Chinese Politeness and Western Politeness}

In Chinese society, the "politeness principle" is different from that of western countries in nature. Chinese politeness principle puts emphasis on distinction. This is the mark of grade differences. This mark is reflected in the aspect of showing social rank relationship. In modern society, it is also used to reflect and maintain the class distinction. This kind of politeness principle is not preferred in western countries. The interpersonal relationship of the westerners is based on a parallel relation. At the same time, in western society, people pursue self-realization and individual struggle, and pay much attention to individual power and individual privacy. Westerners emphasize doing their own business and showing their talent individually. So modesty of Chinese style is naturally looked down upon. From this point, Chinese politeness and western countries' politeness are different.

\section{B. The Differences on the Selection of Politeness Principle}

The tact maxim is the most important in Leech's politeness principle. It is the principle which is often used in interpersonal communication, constituting the core of politeness principle in western culture. In western society, personal interest, individual power and privacy are all believed sacred and inviolable. So, even in the communication between employer and employee, parents and children, teachers and students, communicators must follow the tact maxim to reduce the threat to other person's negative face or reduce the compulsive tone. In English, when people ask someone to do something, they always choose some indirect and euphemistic speech like the following (Gu, 2000):

Will you close the door?

Can (Could) you close the door?

Would you mind closing the door?

Could you possibly close the door?

I was wondering if you could close the door.

However, from the point of view of Chinese tradition, people's behavior is restricted by social expectation. Some people have the right to give the others commands, requests, suggestions, advices, warnings, threatens, etc.; while other people have to accept or fulfill the behavior. For example, directive language can only be used by the elderly to the younger ones, employers to their employees, teachers to their students and parents to their children, or else it is impolite. So in Chinese culture, the respectfulness principle is the politeness phenomenon with strong Chinese cultural characteristics. It lies in the core part of Chinese culture. Chinese tend to debase oneself to show the modesty when someone praises him. In all cultures, modesty is regarded as the performance of politeness. The modesty maxim is also included in Leech's politeness principle, but there are differences in degree of following the principle between westerners and Chinese. Westerners respect others and do not debase themselves. They will accept others' praise with pleasure and say "Thank you" happily, while Chinese will say "Oh, no, no, it isn't so good", etc. under the same situation (Jia, 1997, p.287).

\section{The Differences in the Way of Expressing Politeness between Chinese and Western Countries}

Politeness is the universal phenomenon in all social groups. But every ethnic group has its particular principles or standards. People from different cultural backgrounds will express politeness in different ways. This paper tries to explain it through the following two aspects:

1. Compliment and Response

Compliment is a kind of social speech act which has several functions. It means that it can accomplish different functions in different social environments of daily life communication. According to the surveys done by scholars at home and abroad, other than express appreciation, the dominating function of English complimentary speech is to coordinate the "consistency" in the interaction of communicators. While the functions of Chinese complimentary speech focus on: firstly, making the hearer feel good; secondly, expressing appreciation; thirdly, making use of others. The third function of Chinese complimentary speech is different from those of western culture. In the aspect of content of complimentary speech, there are also cultural differences. The westerners prefer to seek personality, so they always give a compliment on some changes, new ideas or new styles. While Chinese prefer to seek something in common, so the compliment on changes or variations is not so frequently used as that in western countries. As for the response to compliment, the differences are apparent. For example, a foreigner may say "Your dress looks very nice!" when he expresses his appreciation to a Chinese lady, but the Chinese lady answered, "No, it is just ordinary." In Chinese culture, people tend to say "You praise me too much" or "I feel ashamed to hear that" or other self-dispraise words, in order to show their modesty. While in western culture, people who are praised tend to say "Thank you", "I' $m$ glad to hear that", etc. (Deng, 1997, p.76). The former communication fails because the foreigner will feel that this kind of response implies that the Chinese lady consider that he lacks aesthetics and taste and does not know how to judge the style of clothes. Leech's modesty maxim has different importance under English and Chinese, two different cultural backgrounds. Different politeness strategies are used to respond to the complimentary speech in English and Chinese. For English and American, the acceptance of compliment is a kind of respect to the counterpart, and it can avoid threatening the positive face of the counterpart. For Chinese, the self-depreciation is to show self-abasement and respect to the counterpart.

2. Invitation and Acceptance

Chinese always use a threadlike thinking model, and the whole structure of communication includes many words' 
turn. A deal could be done after many times' negotiation. In the polite conversation of inviting and accepting, this situation is more apparently reflected. The inviters always make an invitation for many times to show his sincerity. The Chinese traditional attitudinal warmth is reflected in this situation. The invitee refuses for many times while the inviter insists. On one hand, the invitee intends to find out whether the inviter is sincere, and whether it is just a kind of courtesy but not a real invitation. To accept an invitation immediately is considered to be impolite. On the other hand, only in this insisting way can the sincerity be shown. Therefore, the inviters and invitees usually have negotiation for many times before they can reach the agreement. In our daily life, it is common to hear of dialogues like the following one (Sapir, 1970):

A: Stay with us for the dinner tonight.

B: No, thanks, please don't bother.

A: No trouble at all. Just some dishes, it's not complex. We will have it in just a few minutes.

B: I' m not hungry now so I will go back. Next time I will stay and bother you.

A: Since you are here, make yourself at home. All we can offer you is a simple diet, and we ourselves will have it. Please stay with us. You will give me the face, won't you?

B: Well, then...then... I will stay.

This conversation has gone through a process of inviting-declining-inviting again - declining again - inviting - accepting. It demonstrates the Chinese threadlike thinking model and their euphemistic language fully in communication. While the westerners use a linear type thinking model. In the inviting situation, the most important thing is to make it clear whether he accepts the invitation or not, and at the same time to explain he can attend it on time. In Brown and Levinson's opinion, the insisting invitation is a threat to the hearer's negative face, for the freedom of the hearer is restricted. Due to this, westerners regard the speech acts of suggestion and invitation as acts that may threaten the negative face of others. Once the speech acts are refused, the speaker will not insist, in order to make sure that he is polite to the hearer. Just as the formulation of some scholars, in the speech acts of suggestion and invitation, westerners tend to present a three-step conversational mode like the following (Prosser, 1978):

Speaker: makes the proposal or invitation

Hearer: politely refuses the suggestion or invitation

Speaker: stop making proposal or stop inviting

This mode of inviting and accepting is suitable in western culture. It ensures the freedom of the counterpart and thinks of the negative face of the counterpart. While in Chinese culture, it can not embody the hospitality to a larger extent.

\section{CONCLUSION}

Thus, the Chinese politeness and western politeness are put forward respectively on the basis of Chinese language cultural characteristics and the English language cultural characteristics. They cover many aspects of principles, and will be different from each other due to the different cultures. As a pragmatic principle, the politeness principle of China and western countries are both restricted by their own culture. In cross-cultural communication, people should do their best to use the correct politeness principle, avoid the cultural conflict and get the best effect of communication.

\section{REFERENCES}

[1] Deng Yanchang \& Liu Runqing. (1997). Language and Culture. Beijing: Foreign Language Teaching and Research Press.

[2] Gao Hang. (1997). Face Politeness and Pragmatic. Journal of PLA University of Foreign Languages. 2, $24-28$.

[3] Gu Yueguo. (1992). Pragmatic Politeness and Culture. Foreign Language Teaching and Research. 4, 30 -32.

[4] He Zhaoxiong. (2000). A New Introduction to Pragmatics. Shanghai: Shanghai Foreign Language Education Press.

[5] He Ziran. (1998). Pragmatics and English Learning. Shanghai: Shanghai Foreign Language Education Press.

[6] Jia Yuxin. (1997). Intercultural Communication. Shanghai: Shanghai Foreign Language Education Press.

[7] Geetz, C. (1973). The Interpretation of Culture. New York: Basic Books.

[8] Leech, G. N. (1983). Principles of Pragmatics. London and New York: Longman.

[9] Prosser, M. (1978). The Cultural Dialogue. Boston: Houghton Mifflin.

[10] Sapir, E. (1970). Culture, Language and Personality. Berkeley: University of California Press.

Jiang Zhu was born in Changchun, China in 1971. He received his M.A. degree in linguistics from Changchun University of Science and Technology, China in 2003.

$\mathrm{He}$ is currently an associate professor in School of Foreign Languages, Changchun University of Science and Technology. His research field is cross-cultural communication and applied linguistics.

Yuxiao Bao was born in Taian, China in 1986. She received her B.A. degree in English from Shandong University at Weihai, China in 2009.

She is now studying to get her M.A. degree in linguistics in School of Foreign Languages, Changchun University of Science and Technology. Her research field is cross-cultural communication and applied linguistics. 